\title{
'Seductive promises' and the use of online mathematics instructional programmes in New Zealand primary schools
}

\author{
Lisa Darragh
}

\section{Auckland University}

Internet access and the availability of digital devices in the classroom have grown exponentially. Correspondingly, we have online platforms for learning mathematics that are subscription-based and available for schools or individuals to purchase. Research in mathematics education tends to focus on the benefits to teaching and learning afforded by digital technology, while less attention is given to the implications of having commercial applications in our mathematics classrooms, and their considerable cost. This paper reports on a study of online mathematics instructional programmes in primary schools of New Zealand. Data sources include a survey sent to mathematics leaders of all primary schools, and a discursive analysis of the websites of the most commonly used instructional programmes. There was an obvious similarity found between the promises of the websites and the rationales expressed by school leaders for using the programmes, suggesting that schools are succumbing to the seductive promises of these commercial programmes. It is argued that we need to further examine the implications of using such programmes in our mathematics classrooms, especially in the context of profit-making inside public education.

Keywords: online learning, mathematics instruction, website analysis, discourse analysis

\section{Introduction}

The use of digital technologies and online learning in mathematics education is growing worldwide (Englebrecht et al., 2020). In New Zealand, increasing levels of internet access and growing numbers of digital devices in schools have led to the use of online mathematics instructional programmes (OMIPs) such as Mathletics, Study Ladder, Sumdog (Nicholas \& Fletcher, 2017) and MathsBuddy. OMIPs are subscription-based programmes that offer an individualised and adaptive delivery of mathematics to students, and typically involve a cost that is borne by either the school or the parents. OMIPs form just one part of a broader technological landscape within mathematics education that is seen as inherently positive for learning (e.g., Englebrecht, 2020), yet lacking in the literature is research that takes a more critical approach.

Outside of mathematics education however, concerns about the Ed-tech industry are expressed (Knox et al., 2020; Roberts-Mahoney et al., 2016; Wright \& Peters, 2017). For example, Wright and Peters (2017) note that digital technologies are seen as neutral or benign and are even encouraged in our New Zealand curriculum. However, they go on to argue that allowing Ed-tech companies to profit from public schools is "privatisation by stealth" formed in and by neoliberal ideology. Neoliberalism, with its market-based view of education, is at the heart of critiques of adaptive learning programmes such as OMIPs. These critiques centre on "big data," that is, the massive amounts of information collected from users by private companies, as well as the neoliberal and behaviourist ideology 
inherent in the 'personalised learning' aspect of Ed-tech (Knox et al., 2020; RobertsMahoney et al., 2016; Wright \& Peters, 2017). The notion of a personalised learning programme and automatic assessment certainly appear attractive, but they work to marginalise teacher expertise (Knox et al., 2020) by transferring educational decisions from the public-school classroom to private corporations (Roberts-Mahoney et al., 2016). Furthermore, they utilise a behaviourist pedagogy (Knox et al., 2020).

OMIPs appear to already have a place in New Zealand primary schools (Nicholas \& Fletcher, 2017) and this position is likely to be cemented in the context of pandemic responses that require online learning formats. Therefore, it is worthwhile to try to understand better the promises these commercial programmes make and the rationales used by schools that utilise them. In this paper I report on a study into OMIPs used in New Zealand primary schools. I compare both the schools' rationales for using OMIPs and the marketing promises embedded in the OMIPs' websites. The specific purpose of this paper is to consider how much in alignment are the discourses of websites and schools, and to hypothesise whether the OMIPs deliver a seductive promise that might capture school leaders.

\section{Methods}

I drew from two data sources within a wider study. The first was the responses of school leaders of mathematics to a survey which asked about their rationale for using OMIPs (see also Darragh \& Franke, 2021). The second source was a discursive analysis of the public websites of the four most popular OMIPs, as found in the survey.

The survey contained a mix of closed- and open-ended questions, including school characteristics such as: type, size, location, and decile. Closed questions asked about access to digital devices and internet at home and school, whether OMIPs were used, and if so, which. The open-ended questions asked for: the school's rationale for choosing the OMIPs, the perceived benefits to teachers and students, and any concerns about the programmes. The survey was sent to all New Zealand primary schools during March-April of 2019 and received 477 responses, approximately 24\% of all schools. Descriptive statistics were calculated, and the open-ended questions were analysed thematically.

The website analysis involved firstly taking screenshots of each page of the websites for Mathletics, Study Ladder, MathsBuddy, and Sumdog; these were the top four programmes used according to the survey. The text for each contained approximately 3,000 words. Analysis involved close reading and an open coding process to search for the 'promises' made in the texts.

\section{Findings}

Of the 477 schools responding to the survey, $384(81 \%)$ made use of digital technologies in the teaching of mathematics and 377 (79\%) used an OMIP as part of the mathematics programme. The top four OMIPs used were Mathletics (168 respondents; 45\%), Study Ladder (147 respondents; 39\%), MathsBuddy (75 respondents; 20\%) and Sumdog (73 respondents; $19 \%$ ); clearly schools used more than one programme. In most cases either the school, the parents, or both school and parents paid for the programmes. Just $19 \%$ of schools utilised free programmes only. The majority of schools rationalised the use of the programmes as being to supplement the classroom teaching and to support children's learning and progress in mathematics. Other themes emerging included: 
motivating/engaging for students, homework/home-school link, individualised, digital technology, financial aspects, assessment and feedback, and curriculum aligned. Excluding the question about leaders' concerns, there were altogether 15 broad themes found.

The discursive analysis of the websites generated 19 distinct 'promises' - although much text drew on a number of these promises within a single statement (see Table 1 below for examples). The six main promises were: Assessment and feedback, engagement and motivation, personalised programmes, progress oriented, curriculum aligned, catering to affective issues. These six promises were found on all four websites, and at least 50 instances of each were noted during analysis in the somewhat repetitive website texts. In five of the six cases, it was immediately apparent that much of what the websites promised was remarkably similar to that which the school leaders spoke about in their rationales. Table 1 gives examples of these promises together with a couple of examples from school mathematics leaders.

Table 1

Examples of the promises within website text and school leaders' rationales

\begin{tabular}{|c|c|c|}
\hline Promise & Website example & School leader example \\
\hline $\begin{array}{l}\text { Assessment and } \\
\text { feedback }\end{array}$ & $\begin{array}{l}\text { "Mathletics can produce powerful reports, } \\
\text { providing school and home educators with } \\
\text { deep insights into how classes and } \\
\text { individual learners are progressing" } \\
\text { (Mathletics). }\end{array}$ & $\begin{array}{l}\text { [Because it] informs students } \\
\text { immediately whether their answer } \\
\text { is correct, gives students scores, } \\
\text { graded" } \\
\text { "Easily able to monitor students. } \\
\text { Provides great reporting systems." }\end{array}$ \\
\hline $\begin{array}{l}\text { Engagement and } \\
\text { motivation }\end{array}$ & $\begin{array}{l}\text { "Tables fluency is an essential step } \\
\text { towards becoming a confident learner. } \\
\text { Sumdog Tables provides a new way for } \\
\text { learners to practise their tables whilst also } \\
\text { having fun!" (Sumdog) }\end{array}$ & $\begin{array}{l}\text { "It is a 'fun' way to engage children } \\
\text { in learning/reinforcing their } \\
\text { maths." } \\
\text { "Fun approach to math, interactive, } \\
\text { easy link for school to home } \\
\text { learning." }\end{array}$ \\
\hline $\begin{array}{l}\text { Personalised } \\
\text { programme }\end{array}$ & $\begin{array}{l}\text { "Teachers have a wide range of learning } \\
\text { abilities within classrooms. Our complete } \\
\text { learning programmes and teaching } \\
\text { resources give teachers the power to } \\
\text { create individual learning programmes for } \\
\text { their students" (Study Ladder). }\end{array}$ & $\begin{array}{l}\text { "Mathletics is able to be tailored to } \\
\text { the needs of individual students } \\
\text { and can be monitored easily by } \\
\text { teachers" } \\
\text { "Individualised learning" }\end{array}$ \\
\hline $\begin{array}{l}\text { Progress } \\
\text { oriented }\end{array}$ & $\begin{array}{l}\text { "And you'll start seeing results as early as } \\
\text { the very first lesson!" (Maths Buddy) }\end{array}$ & $\begin{array}{l}\text { "Help with progress and practise } \\
\text { opportunities." } \\
\text { "To support their learning; provide } \\
\text { practice activities to consolidate } \\
\text { learning" }\end{array}$ \\
\hline
\end{tabular}


Curriculum "Built on a foundation of solid curriculumaligned \& Comprehensive led content and designed by a team of veteran educators, Mathletics complements and reinforces schoolwork and classroom learning, with full control in the hands of the parent, tutor or home educator." (Mathletics) ${ }^{1}$
"[Our choice was based on] cost and alignment with NZ maths curriculum"

"Best fit for the NZC and NCEA"

It was very easy to find in the school leaders' rationales examples that matched well to the promises within the OMIP websites. Despite this analysis being done first, in most cases the leaders' rationales had been coded using the exact same terms - highlighting the similarity of language use by websites and school leaders.

There were a couple of exceptions to this synchronicity in the data from the two studies. The sixth main promise in the website data was omitted from the table because it was not reflected in the survey data. This promise was catering to affective issues, for example:

"Students can lose confidence, lose heart and interest, as they continue through their school years. Indeed, generations of students have struggled in vain to conquer maths." (MathsBuddy)

The difference here was unsurprising as this promise appeared to be pitched more at parents than teachers or schools and relied on a deficit positioning of the school that the OMIP promised to solve.

Additionally, there was a strong theme in the school leaders' discourse that was not present in the websites, that is, the OMIPs are most useful as just a part of a balanced classroom programme, or a homework resource:

"To add an option to our maths programmes. We believe in providing a variety of approaches for our students. Some learn best by doing and making, some through conversation, some through online programmes that reinforce group work done with their teacher."

"To complement the teaching that was happening at school, allow students to follow their own independent pathways and to give them a maths programme they can use at home."

The positioning of the OMIPs as only part of the overall programme perhaps runs counter to an OMIP desire to occupy a large share of the mathematics education provision.

\section{Discussion}

In this section I briefly discuss each of the websites' seductive promises and consider an alternative reading of the supposed benefit. Correspondingly, I argue that each of the OMIP promises, whilst appearing to be extremely beneficial to teaching and learning, is in fact primarily a marketing ploy.

\footnotetext{
${ }^{1}$ The quotes are taken from the following websites: https://www.mathletics.com/nzl ; https://pages.sumdog.com/ ; https://www.studyladder.co.nz/ ; https://www.mathsbuddy.co.nz/
} 
Providing quick and easy assessment data for teachers and feedback to students appears to be a great timesaver for teachers. However, the data generated by learners' interaction with the OMIPs are owned by the company. Called "big data" in the literature (Knox et al., 2020; Roberts-Mahoney et al., 2016), this information may be used by the company to optimise the programme and, further, allows the educational decisionmaking to be done by a private company and not the teacher (Knox et al., 2020). Rather than the teacher selecting the learning activities for the student, the programme algorithm assigns the next learning tasks based on the data collected.

Engaging and motivating children in mathematics learning is a key aim of any classroom teacher. However, the games-based methods employed by the OMIPs reinforce superficial mathematics skills and employ behaviourist techniques of reward systems. The software is designed to frame learner choices (Knox et al., 2020) and the games become addictive, reinforcing the desire to play (and to continue using the OMIP), rather than rewarding deep thinking. For example, students may choose the easy tasks in order to more quickly obtain the game reward.

Learning that is personalised and tailored to the individual seems a desirable goal of education. However, as argued by Roberts-Mahoney and colleagues (2016), this is "conceptualizing learning as the acquisition of discrete skills and behavior modification detached from broader social contexts and culturally relevant forms of knowledge and inquiry" (p. 406). It is not in the OMIP's interest to foster team-based learning, nor to emphasise the importance of culturally relevant pedagogy that is specific to the community context. Furthermore, the personalisation of learning works to centre the learner whilst teachers are relegated to a role that merely responds to learner needs, again, marginalising teacher expertise (Knox et al., 2020).

The OMIP promise that students will make progress generates a circular argument. Progress is defined and measured by the system - the progress is seen in incremental steps and rewarded with certificates according to the OMIPs own benchmarks. Whether or not such progress extends to any type of achievement valued by the school is not in the interest of the commercial OMIP.

Finally, the promise that OMIPS are curriculum aligned is important. Despite schools claiming the OMIPs are only one part of a wider programme, the OMIPs state they deliver a comprehensive coverage of the New Zealand curriculum. As a commercial enterprise that aims to grow profit, we might assume they aim to do this via growing their share of the mathematics education provision in New Zealand classrooms. Via the positioning of school as deficit, and the OMIP as catering to affective issues, the OMIPs may be considered a replacement to current mathematics teaching.

As can be seen, each of these main promises, whilst seductive, are certainly problematic. Yet school leaders of primary schools in New Zealand draw on these same promises as part of their rationales for subscribing to OMIPs. Whether leaders have been seduced by the sophisticated marketing of the OMIPs, or whether the OMIPs themselves have drawn upon pre-existing educational discourse in the development of their advertising is not clear; it is perhaps a combination of both. Or perhaps the same words mean different things to OMIPs and school leaders. Whichever the case, the marketing appears successful.

To conclude, the results reported here may provide a basis from which to theorise the role of the curriculum and of the tools that service the curriculum. This may generate a direction for future research, for example, we might consider how the digital context changes our theoretical conception of curriculum or we might examine the tensions 
inherent in such change. However, I argue we need immediately to further interrogate the implications of using commercial OMIPs in our mathematics classrooms. We should remember that the OMIPs come at a cost, and their primary goal is profit. Those promises that seem appealing to education are simultaneously marketed in order to further the profit-making enterprise.

\section{References}

Darragh, L., \& Franke, N. (2021). Online mathematics programs and the figured world of primary school mathematics in the digital era. Mathematics Education Research Journal (online first). https://doi.org/10.1007/s13394-021-00384-9

Engelbrecht, J., Llinares, S., \& Borba, M. (2020). Transformation of the mathematics classroom with the internet. ZDM - Mathematics Education, 52, 825-841.

Knox, J., Williamson, B., \& Bayne, S. (2020). Machine behaviourism: Future visions of "learnification" and "datafication" across humans and digital technologies. Learning, Media and Technology, 45(1), 31-45.

Nicholas, K., \& Fletcher, J. (2017). What is happening in the use of ICT mathematics to support young adolescent learners? A New Zealand experience. Educational Review, 69(4), 474-489. https://doi.org/10.1080/00131911.2016.1237476

Roberts-Mahoney, H., Means, A. J., \& Garrison, M. J. (2016). Netflixing human capital development: Personalized learning technology and the corporatization of K-12 education. Journal of Educational Policy, 31(4), 405-420.

https://doi.org/10.1080/02680939.2015.1132774

Wright, N., \& Peters, M. (2017). Sell, sell, sell or learn, learn, learn? The EdTech market in New Zealand's education system: Privatisation by stealth? Open Review of Educational Research, 4(1), 164-176. https://doi.org/10.1080/23265507.2017.1365623

Lisa Darragh is a senior lecturer at the University of Auckland in the Faculty of Education and Social Work. Lisa completed her PhD in 2014, having studied children's mathematics learner identity as they transition to secondary school. She then spent three years completing a post-doctorate in Santiago, Chile. Prior to her academic life she was a teacher of Year 8 students at Kowhai Intermediate School. Lisa's research interests are about mathematics identity of learners and teachers within the wider social and political context. She teaches mathematics education to pre-service primary teachers and to masters and doctoral students.

Email: I.darragh@auckland.ac.nz

ORCiD: https://orcid.org/0000-0001-7723-1710 